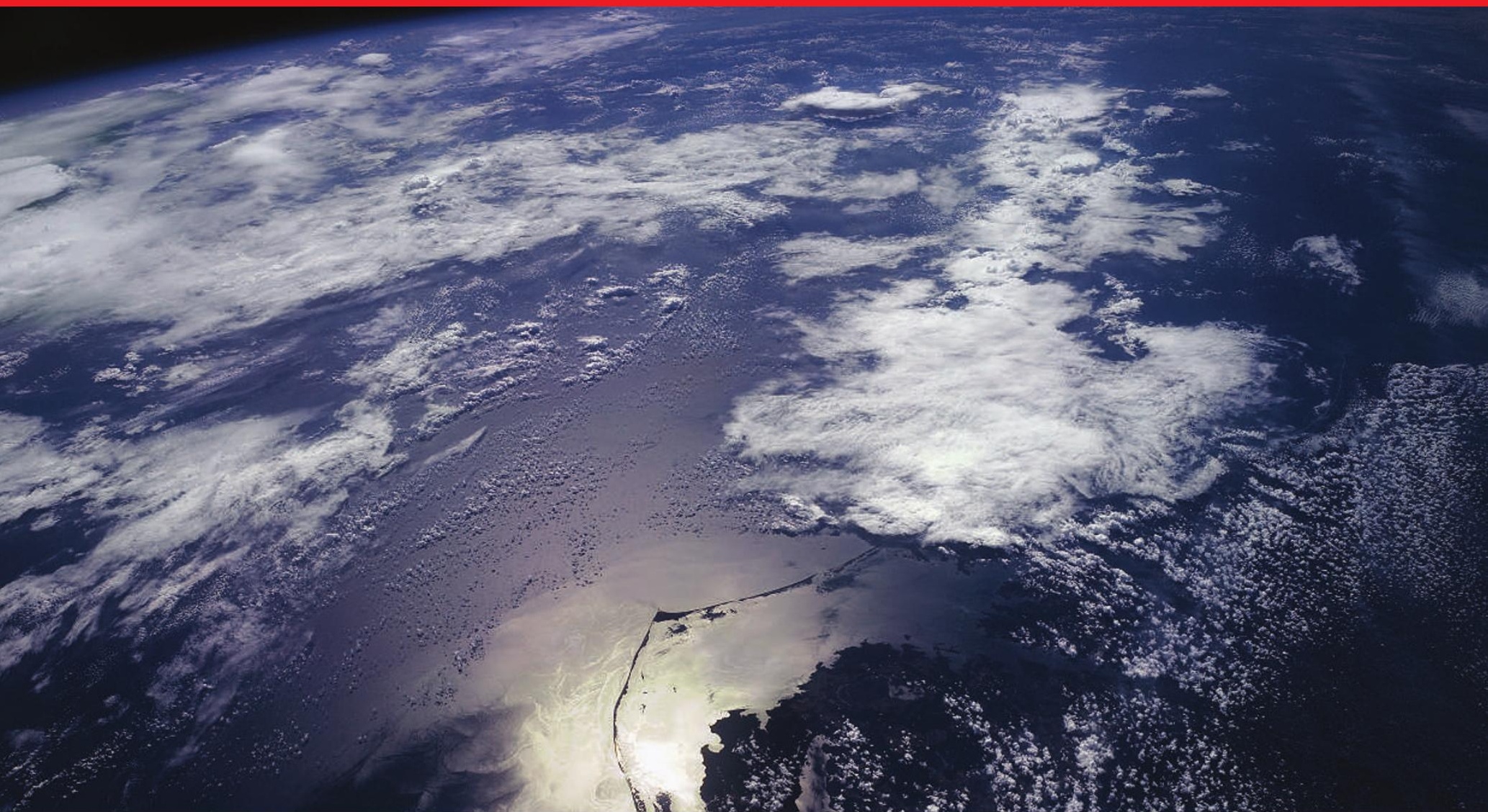

\title{
Churn, churn, churn
}

How the oceans mix their waters is key to understanding future climate change. Yet scientists have a long way to go to unravel the mysteries of the deep. Quirin Schiermeier reports.

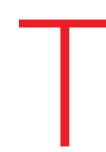

he absence of data is not always a bad thing; it can sometimes make a job a lot easier. In decades past, for instance, climate modellers simply didn't worry too much about how turbulent processes in the ocean (known as ocean mixing) affected the outputs of their models. Not knowing how ocean mixing worked may not have been intellectually fulfilling, but it certainly made the models simpler to run.

But data are now beginning to emerge - and they show, peskily, that mixing is not so simple after all. Information flooding back from instruments such as microstructure profilers, which are towed behind ships to gather data on factors such as temperature and conductivity, has started to quantify exactly how parcels of water mix with each other. In particular, the amount of mixing seems to be much less than models of the ocean would suggest, especially given the temperatures measured at the ocean's depths. Some of the mixing is missing.

As a result, ocean mixing is an increasingly hot topic at conferences. "The field is changing quicker than many would have thought," says Raffaele Ferrari, an oceanographer at the Massachusetts Institute of Technology (MIT) in Cambridge. "It seems unlikely that we know the full story."

The importance of mixing is that it helps the oceans move heat from A - normally near the Equator - to B - which will typically be nearer one of the poles. The best known mechanism is the global conveyor belt, or thermohaline circulation; warm waters move north through the Atlantic before becoming cool and salty enough to sink to the ocean bottom and flow back south, from where they are distributed worldwide ${ }^{1}$. The energy involved is prodigious: 2,000 trillion watts, or two petawatts, some 200 times the rate at which mankind uses energy, and a significant chunk of the energy flow needed to drive Earth's climate.

Since early in the twentieth century it has been known that, without mixing, such a system would stall. The depths would fill up with cold water that, because it was dense, would not resurface, leaving a thin warm layer on top. Warmth is needed to add buoyancy to the bottom waters, and that means mixing them with the waters above. But no one can say for sure where the energy needed that drives this mixing comes from. Some have suggested plankton as paddles (see 'Could tiny creatures stir the whole ocean?'). Others have called down the Moon in support of their theories, proposing tides as the driving force.

The prevailing trade winds between the tropics of Cancer and Capricorn were perhaps the most obvious candidates for stirring the oceans, in principle providing sufficient energy to create a well-mixed upper layer in the tropical oceans. But the amount of mixing near the ocean's surface, as observed by techniques such as microstructure profilers and tracer experiments, is not as high as theoretical calculations would suggest, and not enough to keep the global circulation going.

\section{Stormy weather}

One recent idea is to look not at the regular winds that are the sailor's friend, but the rare ones that spell his doom - specifically, hurricanes. On page 577 of this issue, modeller Matthew Huber of Purdue University in West

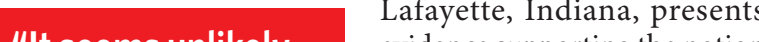
evidence supporting the notion that tropical cyclones play an important part in ocean mixing. Huber's work follows on from a 2001 study that suggested much the same thing ${ }^{2}$. In that earlier work, Kerry Emanuel, a hurricane researcher at MIT, proposed that tropical cyclones mix the upper ocean so well that they are responsible for a staggering amount of heat transfer: 1.4 petawatts. As most other researchers had ignored the role of cyclones 
completely, perhaps thinking them too sporadic to have such a sustained effect, the idea was met with some scepticism. The new study, based on more and better observations, dials this back to an estimated 0.26 petawatts per year - a number that Emanuel says is still "in the right ballpark" for the level of mixing he would expect from cyclones.

Even with the lower mixing rates cited in Huber's study, the very idea that cyclones could substantially contribute to ocean mixing is so surprising that many are still likely to reject it. "At least in the present climate the effect is unlikely to be very large," says Ferrari. But that would not necessarily be the case in the climates of tomorrow (or, for that matter, the climates of yesteryear - see 'Lessons from the past').

What is thought provoking about Emanuel's ideas is that he has also shown that high sea-surface temperatures could push up the strength of tropical storms. Others have speculated that global warming might also make storms more frequent. If cyclones are indeed playing a key role in ocean mixing, then increases in their power and frequency could change that role, and thus the climate. Hurricanes could matter far farther afield than the coasts they batter - their effects could be worldwide. There have long been debates on what global warming means for hurricanes; now we may see one on what hurricanes mean for global warming.

\section{Tales from topographic oceans}

Another source of mixing that was long ignored but is now increasingly accepted is down to the Moon and the tides, and the effect they have, not at shores, but in the oceans'
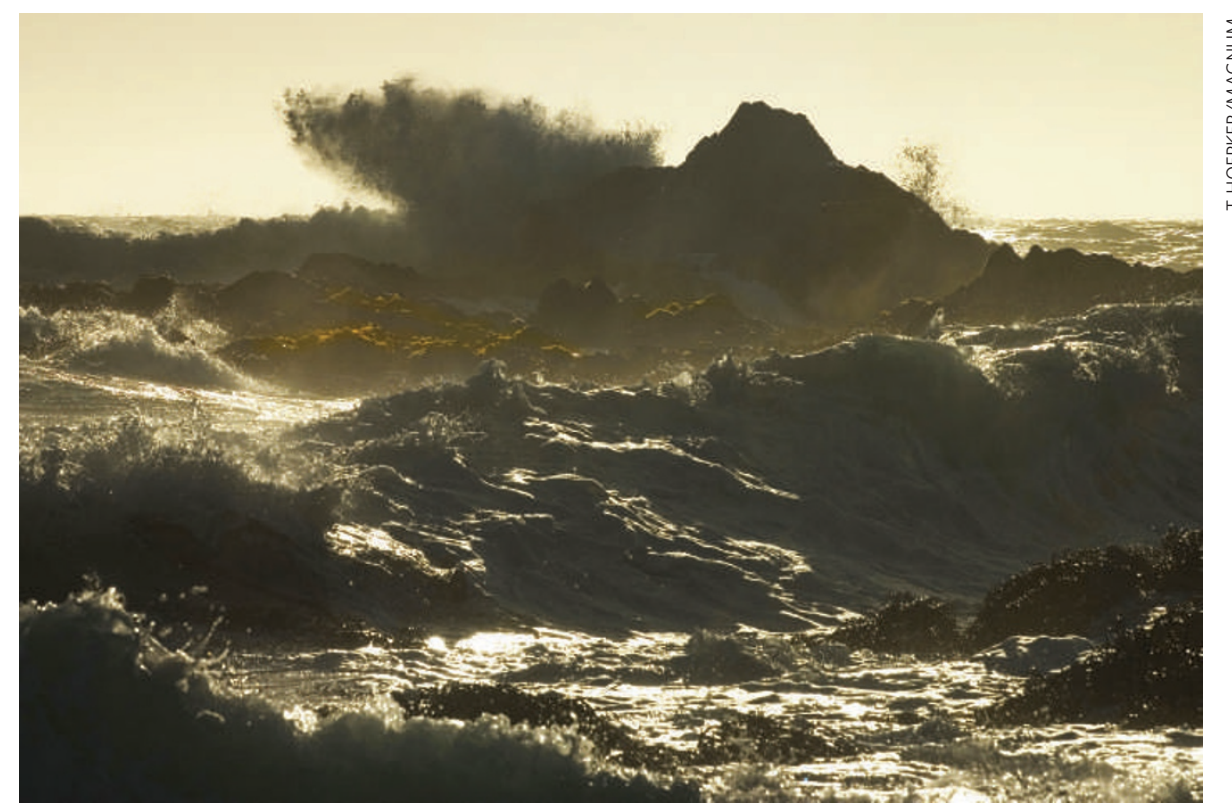

Mix it up: cyclones might help to transfer heat from the Equator to the poles.

depths. In the 1960s and 1970s, conventional oceanographic wisdom held that the considerable energy represented by the ebbing and flowing of tides was dissipated entirely through friction in the shallow coastal areas above continental shelves. But then pioneering oceanographers Walter Munk of the Scripps Institution of Oceanography in La Jolla, California, and Carl Wunsch of MIT proposed that tides penetrate all the way into deep waters, where their flow across the rough seafloor topography helps the water to mix and overcome the forces of gravity ${ }^{3}$. Studies from the Topex/Poseidon satellite that maps sea-surface elevation have since confirmed that tidal energy does indeed get dissipated in the deep ocean ${ }^{4}$.

Other experiments have lent further support to this idea. The Hawaii Ocean Mixing Experiment has quantified the amount of mixing over undersea ridges ${ }^{5}$; it found tides with amplitudes of up to 300 metres sweeping across the flanks of one ridge. Separately, the AnSlope project off Antarctica has looked at the continental shelf surrounding Antarctica and how it affects ocean mixing throughout the Southern Ocean. These projects have shown that most of the mixing takes place at the ocean's boundaries, from the drop-off of the continental slope

\section{Could tiny creatures stir the whole ocean?}

Billions of animals such as krill (pictured) and plankton constantly plough through the ocean's waters, from the tropics to the poles. Could their swimming actually help mix the oceans? "The idea is so fascinating, some would rather hope it is true," says Carl Wunsch, an oceanographer at the Massachusetts Institute of Technology in Cambridge.

The idea of 'biomixing' recently underwent something of a revival. Scientists reported last year ${ }^{8}$ that large schools of krill stir a wellstratified fjord along the coast of British Columbia, Canada. Another study ${ }^{9}$, also published last year, calculated that the overall amount of energy supplied by the swimming motion was substantial. Marine life, the authors suggest, could supply up to half of the mechanical energy required worldwide to mix cold waters to the surface. If it is real, biomixing will be a serious complication for ocean modellers.

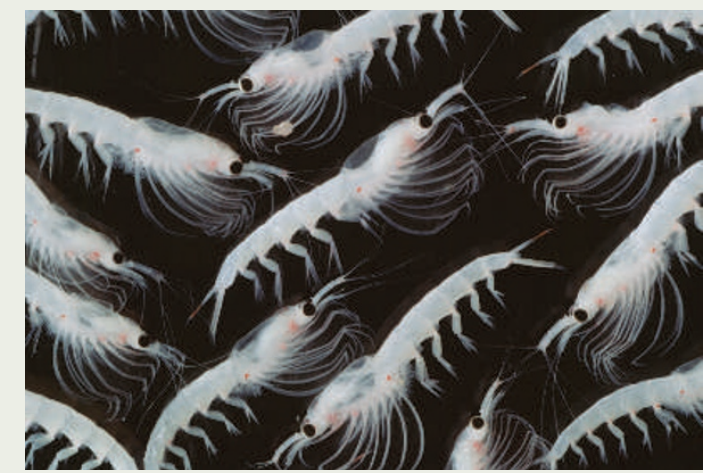

However, the jury remains out as to whether biomixing really has that great an effect. Even if marine animals do dissipate large amounts of energy through their
They will "need to start thin ( biology," says Wunsch. "That's a tough one." swimming, the resulting mixing of the waters may be small. The problem is that most or all of the energy from moving critters is converted into frictional heat, rather than being available for shifting heavy water.

"Mixing efficiency has simply been ignored," says Andy Visser, a marine physicist at the Danish Institute for Fisheries Research in Charlottenlund. "Friction releases heat - that's why basic physics should tell you that there can never be much biomixing." 
to the tall mid-ocean ridges that run along the middle of the sea floor. Mixing doesn't occur everywhere to the same extent. It happens more around and above rough mountainous regions on the sea floor than, say, in the vast abyssal plains. This variability from place to place further complicates modellers' efforts to capture the mixing accurately.

As always, new observations could help. Researchers are unleashing more microstructure profilers, along with remote sensing of sea-surface temperatures and sea-level anomalies, to keep trying to track down the missing mixing. Among other things, they need better to understand the role of 'mesoscale' eddies, some 50 to 100 kilometres across, that swirl around some parts of the oceans mixing water and affecting biological productivity ${ }^{6}$.

Meanwhile, modellers are far from keeping up. Until now they have mostly pretended that mixing occurs uniformly throughout the ocean, and everywhere at the same rate. No one believes that is how the real ocean behaves; few, if any, think it is even a reasonable approximation for a functional climate model. "It's a really serious weak point," says Olivier Marchal, an ocean modeller at the Woods Hole Oceanographic Institution in Massachusetts.

Without capturing the complexities of mixing better, the models will be hard put to capture how climate can be expected to change thanks to the greenhouse effect. For example, most researchers expect the oceans to become less dense.

But that could change, depending on a key mixing parameter, called diffusivity, that most

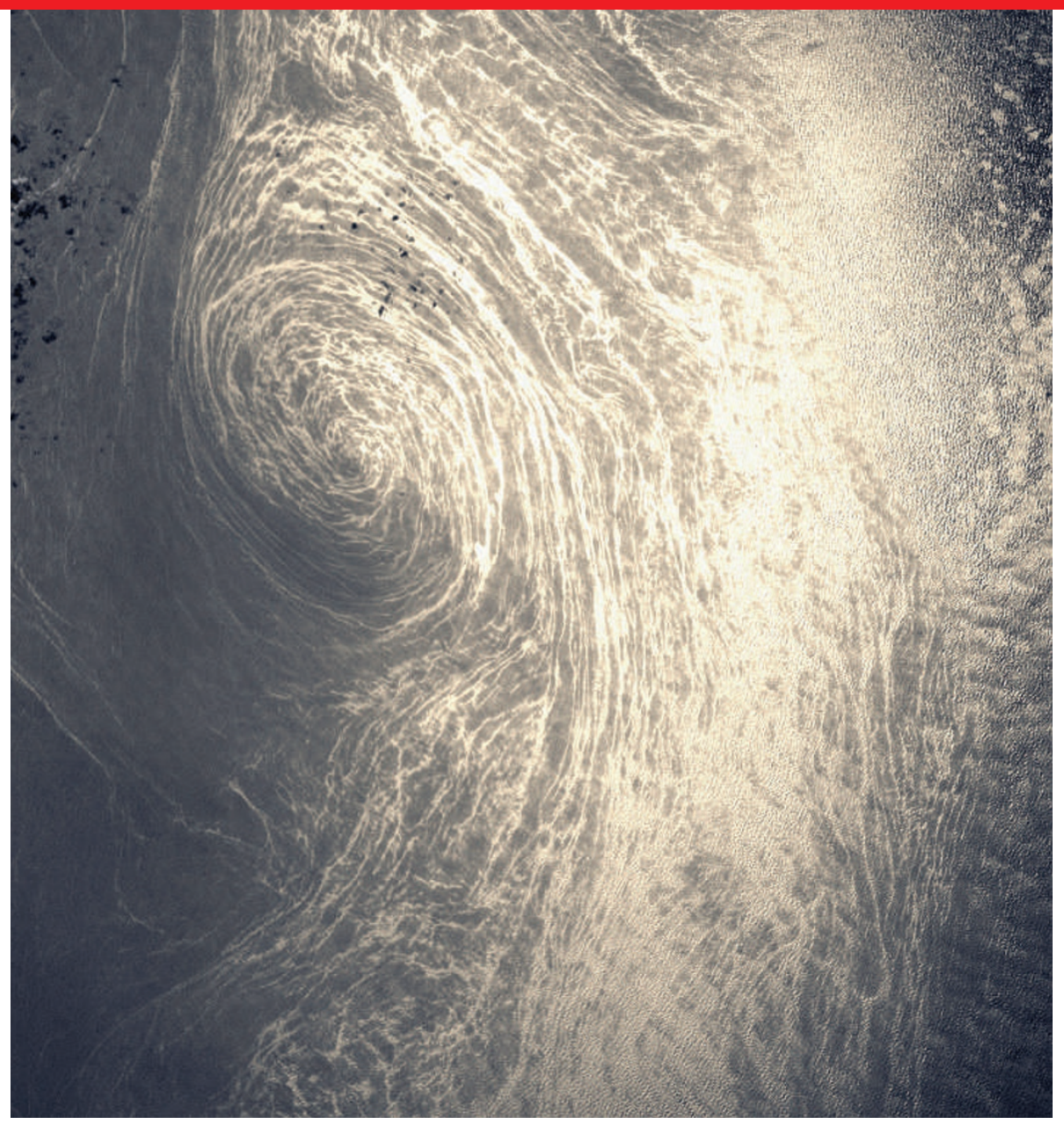

Eddies such as those seen in the Gulf Stream may play a part in mixing the oceans' water.

computer models have so far regarded as fixed. A changing mixing in the models could ultimately alter our view on key components of the climate system, such as the thermohaline circulation; in some models increased mixing could render it more powerful ${ }^{7}$. Researchers would be better off accepting this idea, many say, and

\section{Lessons from the past}

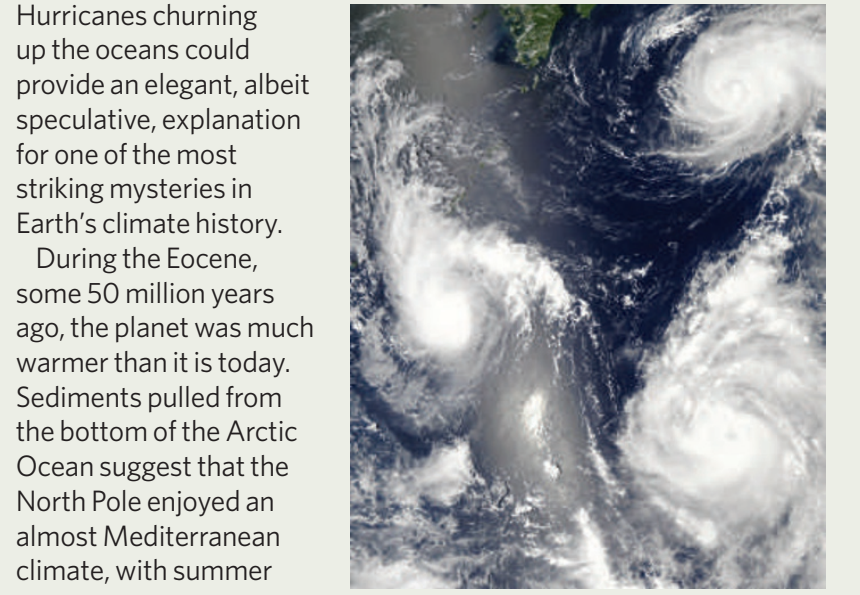

temperatures as warm as $24{ }^{\circ} \mathrm{C}$ (ref. 10).

Climate models provide no adequate explanation. And the extraordinary down? Many scientists, including Kerry Emanuel of the Massachusetts Institute of Technology in Cambridge, have speculated about the possibility. They think that strong and frequent cyclones may have enhanced mixing in the upper layers of the ocean, helping to tropics to the poles.

But so far there is little climates produce more tropical storms. The

temperatures in the Arctic imply that the tropics must have been excessively hot. But could intense cyclones have helped to cool things

in geological deposits ha produced ambivalent results at best, says Emanuel. transport heat from the evidence that warmer

moving forward with new ways to quantify the problem. But working the fine details of mixing into global models will remain a tall order.

With so many new findings, those who study ocean mixing are scrambling to incorporate them all. And scientists may soon have a rule book by which to conduct their future research. Robin Muench, an oceanographer with the Earth and Space Research Institute in Seattle, Washington, leads a working group set up by the International Council for Science. Its goal is to identify the rate of mixing in the oceans as a whole as well as in specific regions where mixing is known to occur (or not).

In July, the group is slated to deliver its final report in Perugia, Italy, which should help clarify the research agenda. And with that, the modellers will have their next couple of years' work laid out for them.

Quirin Schiermeier is a correspondent for Nature in Munich.

1. Schiermeier, Q. Nature 439, 256-260 (2006).

2. Emanuel, K. J. Geophys. Res. 106, 14771-14782 (2001).

3. Munk, W. \& Wunsch, C. Deep Sea Res. 45, 1977-2010 (1998).

4. Egbert, G. D. \& Ray, R. D. Nature 405, 775-778 (2000)

5. Rudnick, D. L. et al. Science 301, 355-357 (2003).

6. McGillicuddy, D. J. et al. Science 316, 1021-1026 (2007).

7. Nilsson, J., Brostöm, G. \& Walin, G. J. Phys. Oceanogr. 33, 2781-2795 (2003) Bartlett, K. P. Science 313, 1768-1770 (2006).
8. Kunze, E. Dower, J. F. Beveridge, I., Dewey, R. \&

9. Dewar, W. K. et al. J. Marine Res. 64, 541-561 (2006).

10. Brinkhuis, H. et al. Nature 441, 606-609 (2006). 